\title{
Current Status of Peroral Endoscopic Myotomy
}

\author{
Young Kwan Cho and Seong Hwan Kim \\ Division of Gastroenterology and Hepatology, Department of Internal Medicine, Eulji University College of Medicine, Seoul, Korea
}

Peroral endoscopic myotomy (POEM) has been established as an optional treatment for achalasia. POEM is an endoluminal procedure that involves dissection of esophageal muscle fibers followed by submucosal tunneling. Inoue first attempted to use POEM for the treatment of achalasia in humans. Expanded indications of POEM include classic indications such as type I, type II, type III achalasia, failed prior treatments, including Botulinum toxin injection, endoscopic balloon dilation, laparoscopic Heller myotomy, and hypertensive motor disorders such as diffuse esophageal spasm, jackhammer esophagus. Contraindications include prior radiation therapy to the esophagus and prior extensive esophageal mucosal resection/ablation involving the POEM field. Most of the complications are minor and self-limited and can be managed conservatively. As POEM emerged as the main treatment for achalasia, various adaptations to tunnel endoscopic surgery have been attempted. Tunnel endoscopic surgery includes POEM, peroral endoscopic tumor resection, gastric peroral endoscopic pyloromyotomy. POEM has been widely accepted as a treatment for all types of achalasia, even for specific cases such as achalasia with failed prior treatments, and hypertensive motor disorders. Clin Endosc 2018;51:13-18

Key Words: Peroral endoscopic myotomy; Achalasia; Natural orifice transluminal endoscopic surgery; Heller myotomy

\section{INTRODUCTION}

The annual incidence of achalasia is 1 per 100,000, with a prevalence of 10 per 100,000 people, which makes it a very rare disease. ${ }^{1}$ Symptoms of achalasia include dysphagia for solids and liquids, chest pain, loss of weight, heartburn, and aspiration pneumonia. ${ }^{2}$ The Eckardt score is used to assess the degree of achalasia symptoms. ${ }^{3}$ Esophageal manometry, the gold standard test for the diagnosis of achalasia, reveals incomplete relaxation of the lower esophageal sphincter (LES) and aperistalsis of the esophageal body. ${ }^{4}$ Various treatment options for achalasia aim at relieving symptoms by reducing resting pressure in the LES. Conventional treatments include oral pharmacologic therapies with nitrate and calcium chan-

Received: October 17, 2017 Revised: December 16, 2017

Accepted: January 10, 2018

Correspondence: Seong Hwan Kim

Division of Gastroenterology and Hepatology, Department of Internal Medicine, Eulji University College of Medicine, 68 Hangeulbiseok-ro, Nowon-gu, Seoul 01830, Korea

Tel: +82-2-970-8209, Fax: +82-2-970-8621, E-mail: shkim@eulji.ac.kr

(c) This is an Open Access article distributed under the terms of the Creative Commons Attribution Non-Commercial License (http://creativecommons.org/ licenses/by-nc/3.0) which permits unrestricted non-commercial use, distribution, and reproduction in any medium, provided the original work is properly cited. nel blockers, botulinum toxin injection, pneumatic dilation, and surgical myotomy. ${ }^{5}$ As endoscopic submucosal dissection (ESD) emerged as a treatment for gastric neoplasm with the development of endoscopic techniques and devices, the submucosal layer became a manipulatable region. As the ESD technique and endoscopic submucosal surgery evolved, natural orifice transluminal endoscopic surgery (NOTES) was also introduced. Peroral endoscopic myotomy (POEM) represents a NOTES approach to Heller myotomy. POEM is an endoscopic procedure to divide the circular muscles mainly in the esophageal muscle fibers across the esophagogastric junction (EGJ) and into the stomach. ${ }^{6}$ Pasricha et al. first suggested the feasibility of POEM in a porcine model. ${ }^{7}$ Inoue et al. were the first to try POEM for treating achalasia in humans. ${ }^{6}$ Since then, the use of POEM has quickly spread worldwide. This paper will focus on the current procedure, outcomes, complications, and future aspects of POEM.

\section{POEM PROCEDURE}

Patients are evaluated before undergoing POEM; after the procedure is performed, postoperative complications and effica- 
cy of POEM should be evaluated. Assessment of the severity of symptoms and special tests may be needed for evaluation of the patient prior to the procedure. The Eckardt score is used to assess the degree of achalasia symptoms. The Eckardt score was evaluated from 0 to 3 points for weight loss, dysphagia, posterior sternal pain, and reflux symptoms. Higher the score, greater the severity of the symptoms, and it is also helpful to determine the therapeutic effect (Table 1). ${ }^{3}$ Esophageal manometry, esophagography, and endoscopy are used for the diagnosis of achalasia. Patients suspected of achalasia require at least two tests for diagnosis and in some cases all three tests are necessary. The esophagogram findings include delayed passage of barium, esophageal enlargement, esophageal ataxia, and narrow gastric esophageal junction, which is characterized by a "bird beak" appearance and helps to determine the presence of sigmoid type achalasia. ${ }^{9}$ The role of endoscopy in the diagnosis of achalasia is to exclude mechanical obstruction; pseudoachalasia mistaken for achalasia. ${ }^{10}$ On high resolution manometry, achalasia has been classified into three types.. Type I has incomplete LES opening and aperistalsis, type II has panesophageal pressurization, and type III has no normal peristalsis, but distal esophageal spasm. ${ }^{11}$ Patient maintains a liquid diet for 2 days before the procedure. Intravenous antibiotics should be prescribed for three days until the procedure day, following additional oral antibiotics for three or four days. The POEM procedure is carried out under general anesthesia. Carbon dioxide gas should be used during the procedure to decrease the risk of complications including mediastinal emphysema and air embolization. An upper gastrointestinal endoscope equipped with water jet and transparent cap is used. Triangle-tip knife (TT knife; Olympus Medical Systems, Tokyo, Japan), Hybrid Knife (ERBE, Tübingen, Germany) have been used for POEM. TT knife has the advantage of facilitating selective dissection of the circular muscle layer, whereas Hybrid knives have the advantage of being infusible and shortening the procedure time. For electrocautery, an electrosurgical unit is used. The site of mucosal incision in the anterior approach is at the 2 oclock position mainly, but in the posterior approach, the 5 oclock position is used in patients who have undergone laparoscopic Heller myotomy (LHM). The length of myotomy should be at least 7

Table 1. Eckardt Score

\begin{tabular}{lllll}
\hline $\begin{array}{c}\text { Score } \\
\text { (kg) }\end{array}$ & $\begin{array}{c}\text { Weight loss } \\
\text { None }\end{array}$ & Dysphagia & $\begin{array}{c}\text { Retrosternal } \\
\text { pain }\end{array}$ & Regurgitation \\
\hline 0 & None & None & None \\
1 & $<5$ & Occasional & Occasional & Occasional \\
2 & $5-10$ & Daily & Daily & Daily \\
3 & $>10$ & Each meal & Each meal & Each meal \\
\hline
\end{tabular}

$\mathrm{cm}$, with $2 \mathrm{~cm}$ extending into the gastric side, and even longer in spastic esophageal disorders (SEDs) such as Type III achalasia. The detailed procedure of POEM is as follows (Fig. 1).

Step 1. Submucosal injection- Submucosal injection is performed using a solution of saline mixed with indigocarmine dye to create separation between the mucosa and submucosa.

Step 2. Mucosal incision- Mucosal incision is made in the 2-oclock position, with a knife, up to $2 \mathrm{~cm}$ vertically in order to close easily.

Step 3. Submucosal tunneling- A submucosal tunnel is formed using a triangle tip knife and passed over the EGJ and 3 to $4 \mathrm{~cm}$ down into the cardia.

Step 4. Myotomy- Myotomy is performed from the proximal esophagus up to 2 to $3 \mathrm{~cm}$ below the EGJ, to a point $2 \mathrm{~cm}$ below the mucosal entry.

Step 5. Closure- The mucosal incision site is closed with endoclips.

Barium esophagogram and endoscopy should be performed on postoperative day 1 to rule out complications such as presence of leakage, bleeding in the tunnel. After confirming the absence of any complication, liquid diet will be initiated, and if the patient tolerates the diet, he will be discharged. Eckardt score, esophageal manometry, esophagogram, endoscopy will be checked to evaluate the efficacy of POEM after discharge. ${ }^{12}$ A decrease in the Eckardt score by more than 3 points is considered as a clinical success. ${ }^{13}$

\section{INDICATIONS AND CONTRAINDICATIONS}

Inoue et al. first reported the POEM trial for achalasia in humans. ${ }^{6}$ The application of POEM was limited to achalasia initally. ${ }^{6}$ There have been attempts since then, for use of the technique beyond the classic indication. Sharata et al. reported safety and effectiveness of POEM after preoperative endoscopic balloon dilatation or botulinum toxin injection, Zhou et al. reported safety and effectiveness of POEM for failed Heller myotomy. ${ }^{14,15}$ Importantly, POEM has the advantage of the ability to access the entire length of the esophageal body, an extensive myotomy being possible without limitation. ${ }^{16}$ Owing to these advantages, the application of POEM in SEDs including diffuse esophageal spasm and jackhammer eosphagus has been attempted, which requires a more extensive than achalasia. Shiwaku et al. and Ko et al. reported the feasibility of POEM for diffuse esophageal spasm and jackhammer esophagus respectively ${ }^{17,18}$ As the applications of POEM increase, an expanded indication of POEM is suggested in the International Peroral Endoscopic Myotomy Survey (IPOEMS) study, ${ }^{19}$ which includes the classic indication for achalasia and past history of 

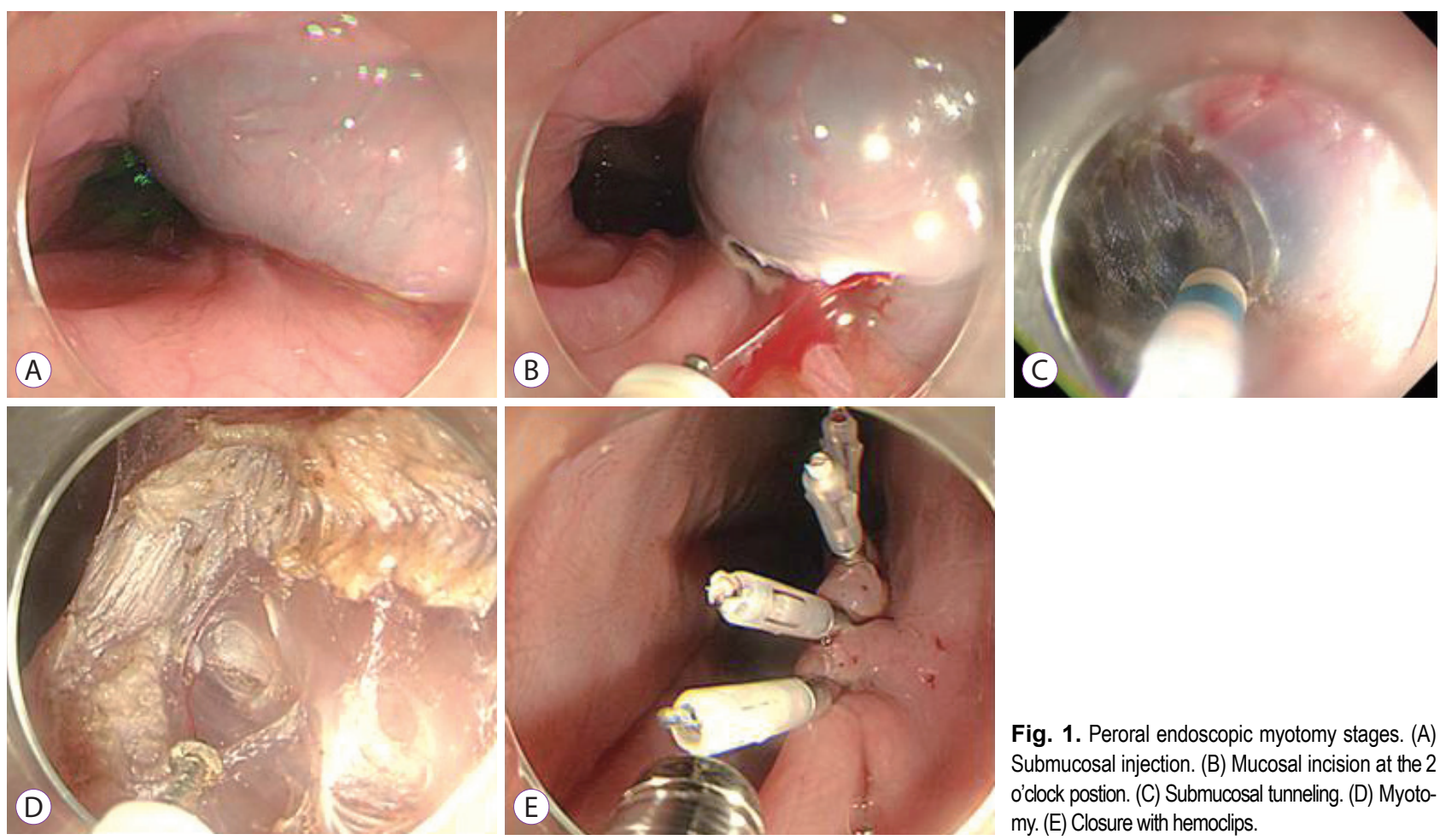

Fig. 1. Peroral endoscopic myotomy stages. (A) Submucosal injection. (B) Mucosal incision at the 2 o'clock postion. (C) Submucosal tunneling. (D) Myotomy. (E) Closure with hemoclips.

failed treatments. Moreover, contraindications of POEM have been mentioned in the IPOEMS study, which include previous radiation therapy to the esophagus, past history of wide esophageal mucosal resection or ablation involving the POEM field, and various conditions with high morbidity (Table 2).

\section{OUTCOME}

Many studies have demonstrated the efficacy of POEM, since Inoue et al. first reported the use of POEM in humans (Table 3). ${ }^{20-30}$ There were four meta-analysis studies on the outcome of POEM, and all the four studies showed efficacy of POEM with a reduction in both the Eckardt score and LES pressure. ${ }^{31-34}$ Technical success was 97\%, and clinical success (Eckardt score $\leq 3$ ) was 93\%-98\%, symptom relief was maintained at 1, 6 and 12 months after treatment and median follow up duration was 6-8 months. ${ }^{31,33}$ Non-randomized studies comparing POEM to LHM showed conflicting results. ${ }^{35-37}$ Meta-analysis studies showed that there were no differences between the two groups with regard to reduction in the Eckhart's score, post-operative pain scores, analgesic requirements, length of hospital stay, adverse events, reflux symptoms, and esophagitis. ${ }^{31,33}$ In the future, randomized comparative studies of POEM and LHM are necessary. Ngamruengphong et al. reported a long term result of POEM for achalasia, with a clinical success rate of $91 \%$ in patients who were followed up for at least 2 years. ${ }^{38}$ According
Table 2. Expanded Indications and Contraindications of Peroral Endoscopic Myotomy

\begin{tabular}{l}
\hline Expanded indications \\
\hline Classic indication: type I, type II, type III achalasia \\
Failed prior treatments: botulinum toxin injection, endoscopic \\
balloon dilation, laparoscopic Heller myotomy \\
Hypertensive motor disorders: diffuse esophageal spasm, \\
jackhammer esophagus \\
Contraindications
\end{tabular}

Prior radiation therapy to the esophagus

Prior extensive esophageal mucosal resection/ablation involving the POEM field

Severe pulmonary disease

Severe thrombocytopenia

Cirrhosis with portal hypertension but no significant esophageal varices

POEM, peroral endoscopic myotomy.

to the subtype of achalasia, there were no differences between type I, type II and, type III achalasia in terms of reduction in the Eckhart's score, LES pressure, integrated relaxation pressure. $^{39}$ Khan et al. reported a meta-analysis of POEM in SED including type III achalasia, diffuse esophageal spasm, and jackhammer esophagus. ${ }^{40}$ Clinical success rates of POEM for SED, type III achalasia, diffuse esophageal spasm, jackhammer esophagus were $87 \%, 98 \%, 88 \%, 72 \%$, respectively. ${ }^{40}$ 
Table 3. Efficacy of Peroral Endoscopic Myotomy

\begin{tabular}{|c|c|c|c|c|}
\hline Study & $\begin{array}{l}\text { Patient } \\
\text { (n) }\end{array}$ & $\begin{array}{c}\text { Eckardt score } \\
\text { (pre/post) }\end{array}$ & $\begin{array}{c}\text { LES pressure } \\
\text { (pre/post) (mm Hg) }\end{array}$ & $\begin{array}{l}\text { Follow-up } \\
\text { (mo) }\end{array}$ \\
\hline Ling et al. $(2014)^{20}$ & 87 & $7.1 / 0.4$ & $32.4 / 3.8$ & 12 \\
\hline Wang et al. $(2015)^{21}$ & 46 & $8.4 / 2.7$ & $39.4 / 24.4$ & 3 \\
\hline Liu et al. $(2015)^{22}$ & 3 & $6.83 / 0.46$ & $29.5 / 10.3$ & 6 \\
\hline Ramchandani et al. $(2016)^{23}$ & 220 & $7.2 / 1.18$ & $37.5 / 15.2$ & 12 \\
\hline Costamagna et al. $(2012)^{24}$ & 11 & $7.1 / 1.1$ & $45.1 / 16.9$ & 1 \\
\hline Inoue et al. $(2015)^{25}$ & 500 & $6.0 / 1.0$ & $25.4 / 13.4$ & 36 \\
\hline Shiwaku et al. $(2016)^{26}$ & 100 & $5.9 / 0.8$ & $43.6 / 20.9$ & 3 \\
\hline Lee et al. $(2013)^{27}$ & 13 & $6.4 / 0.4$ & $30.3 / 15.3$ & 3 \\
\hline Teitelbaum et al. $(2014)^{28}$ & 41 & $7 / 1$ & $28 / 11$ & 12 \\
\hline Sharata et al. $(2015)^{29}$ & 100 & $6 / 1$ & $44.3 / 22.2$ & 16 \\
\hline Khashab et al. $(2016)^{30}$ & 60 & $8 / 1.19$ & $29 / 11$ & 4 \\
\hline
\end{tabular}

LES, lower esophageal sphincter.

\section{COMPLICATIONS}

Early complications include mucosal injury, esophageal perforation, substantial bleeding requiring interventions, subcutaneous emphysema, pneumothorax, pneumomediastinum, pneumoperitoneum, and pleural effusion. ${ }^{35}$ Late complications include symptomatic gastroesophageal reflux, erosive esophagitis and abnormal acid exposure following a 24-hour $\mathrm{pH}$ monitoring study (Table 4). ${ }^{34}$ Most of the complications are self-limited and can be managed conservatively. The mucosal defect can be closed by multiple clips, fibrin sealant, over-thescope-clips and endoscopic suture device. ${ }^{41-44}$ Bleeding can be managed by endoscopic hemostasis. ${ }^{45}$ Pneumoperitoneum can be managed with Veress needle technique in most cases, and most case of pleural effusion and pneumothorax resolve spontaneously. Severe pleural effusions require thoracotomy with drainage. Mediastinitis is an uncommon but major complication of POEM and it often requires surgical drainage. Delayed bleeding is rare and can be managed conservatively in most cases by observation and transfusion. ${ }^{46,47}$ Patients who have symptomatic gastroesophageal reflux can be satisfactorily managed with proton pump inhibitors and antacids. ${ }^{31}$ POEM has shown no mortality in published reports.

\section{CONSIDERATIONS}

\section{Myotomy site}

Which is better between anterior myotomy and posterior myotomy?

Anterior myotomy at the 2 oclock position has the advan-
Table 4. Complications of Peroral Endoscopic Myotomy

\begin{tabular}{lc}
\hline Early complication & $\%$ \\
\hline Mucosal injury & 4.8 \\
Esophageal perforation & 0.2 \\
Major bleeding & 0.2 \\
Subcutaneous emphysema & 7.5 \\
Pneumothorax & 1.2 \\
Pneumomediastinum & 1.1 \\
Pneumoperitoneum & 6.8 \\
Pleural effusion & 1.2 \\
\hline Late complication & $\%$ \\
\hline Symptomatic GERD & 8.5 \\
Esophagitis on EGD & 13 \\
Abnormal exposure on 24-hour pH study & 47 \\
\hline
\end{tabular}

GERD, gastroesophageal reflux disease; EGD, esophagogastroduodenoscopy.

tage of reducing gastroesophageal reflux by avoiding damage to the angle of His and the sling muscle bundle along the greater curvature of the stomach. ${ }^{48}$ Posterior myotomy at the 5 oclock position has the advantage of fast and convenient access to the EGJ with the landmark of the spinal cord and the angle of His. ${ }^{49,50}$ Posterior myotomy has been reported to be useful in failed surgical Heller myotomy, advanced sigmoid type achalasia with megaesophagus, and redoPOEM and POEM post-Heller myotomy due to provision of better recognition of the dissection plane. ${ }^{15,41,51,52}$ However, since no studies have compared anterior myotomy and posterior myotomy, prospective clinical trial studies are necessary. 


\section{Myotomy depth}

\section{Which is better between circular muscle myotomy and full thick- ness myotomy?}

There were no significant differences in symptom relief, procedure-related parameters and adverse events, manometry outcomes, and reflux complications between circular muscle myotomy and full thickness myotomy. ${ }^{53,54}$ Full-thickness myotomy is associated with a reduction in the procedure time but a higher rate of postoperative gastroesophageal reflux disease. ${ }^{53,55}$ Intentional full-thickness myotomy is not essential to treat achalasia.

\section{FUTURE}

A key point enabling the use of POEM is a submucosal tunneling technique that manipulates the submucosal layer. As POEM emerged as the main treatment of achalasia, various adaptations in tunnel endoscopic surgery have been attempted. Tunnel endoscopic surgery includes POEM, peroral endoscopic tumor resection (POET), and gastric peroral endoscopic pyloromyotomy (G-POEM). ${ }^{50}$ POET is a way to completely remove a submucosal tumor through submucosal tunneling, particularly for esophageal, EGJ and gastric cardia tumors originating from the muscularis propria. ${ }^{56}$ POET has shown promising results in terms of efficacy and safety, however, further studies are necessary. ${ }^{57-59}$ Since Khashab et al. first reported human G-POEM, it has been an emerging novel endoscopic technique as an incisionless pyloroplasty for refractory gastroparesis. ${ }^{60}$ Several studies have shown feasibility and promising results of G-POEM, however, it has limitations due to a restricted number of studies and lack of a formalized protocol. ${ }^{61-63}$ Thus, further large scale studies are necessary.

\section{CONCLUSIONS}

POEM is a safe and effective option for treating type I, type II, type III achalasia, and even for specific cases such as achalasia with failed prior treatments, Botulinum toxin injection, endoscopic balloon dilation, LHM and hypertensive motor disorders. However, large-scale studies and long-term outcomes are required. POEM has expanded the scope of adaptation to tunnel endoscopic surgeries such as POET and G-POEM, which also require larger scale studies with longterm outcomes.

\section{Conflicts of Interest}

The authors have no financial conflicts of interest.

\section{Acknowledgments}

A kind word of thanks to Prof. Joo Young Cho, Cha University for figure of POEM.

\section{REFERENCES}

1. Francis DL, Katzka DA. Achalasia: update on the disease and its treatment. Gastroenterology 2010;139:369-374.

2. Richter JE. The diagnosis and misdiagnosis of achalasia: it does not have to be so difficult. Clin Gastroenterol Hepatol 2011;9:1010-1011.

3. Eckardt VF, Aignherr C, Bernhard G. Predictors of outcome in patients with achalasia treated by pneumatic dilation. Gastroenterology 1992;103:1732-1738.

4. Verlaan T, Rohof WO, Bredenoord AJ, Eberl S, Rösch T, Fockens P. Effect of peroral endoscopic myotomy on esophagogastric junction physiology in patients with achalasia. Gastrointest Endosc 2013;78:39-44.

5. Campos GM, Vittinghoff E, Rabl C, et al. Endoscopic and surgical treatments for achalasia: a systematic review and meta-analysis. Ann Surg 2009;249:45-57.

6. Inoue $\mathrm{H}$, Minami H, Kobayashi $\mathrm{Y}$, et al. Peroral endoscopic myotomy (POEM) for esophageal achalasia. Endoscopy 2010;42:265-271.

7. Pasricha PJ, Hawari R, Ahmed I, et al. Submucosal endoscopic esophageal myotomy: a novel experimental approach for the treatment of achalasia. Endoscopy 2007;39:761-764.

8. Richter JE. Oesophageal motility disorders. Lancet 2001;358:823-828.

9. Hart P, Francis D. Barium esophagram remains a highly sensitive screening examination for the diagnosis of achalasia: 3. Am J Gastroenterol 2009;104(Suppl 3):S1.

10. Kahrilas PJ, Kishk SM, Helm JF, Dodds WJ, Harig JM, Hogan WJ. Comparison of pseudoachalasia and achalasia. Am J Med 1987;82:439-446.

11. Bredenoord AJ, Fox M, Kahrilas PJ, Pandolfino JE, Schwizer W, Smout AJ. Chicago classification criteria of esophageal motility disorders defined in high resolution esophageal pressure topography. Neurogastroenterol Motil 2012;24 Suppl 1:57-65.

12. Teitelbaum EN, Hungness ES. Peroral endoscopic myotomy periprocedural evaluation: predicting and measuring outcomes. Tech Gastrointest Endosc 2013;15:135-139.

13. von Renteln $\mathrm{D}$, Inoue $\mathrm{H}$, Minami $\mathrm{H}$, et al. Peroral endoscopic myotomy for the treatment of achalasia: a prospective single center study. Am J Gastroenterol 2012;107:411-417.

14. Sharata A, Kurian AA, Dunst CM, Bhayani NH, Reavis KM, Swanström LL. Peroral endoscopic myotomy (POEM) is safe and effective in the setting of prior endoscopic intervention. J Gastrointest Surg 2013;17:1188-1192.

15. Zhou PH, Li QL, Yao LQ, et al. Peroral endoscopic remyotomy for failed Heller myotomy: a prospective single-center study. Endoscopy 2013;45:161-166.

16. Khashab MA, Messallam AA, Onimaru M, et al. International multicenter experience with peroral endoscopic myotomy for the treatment of spastic esophageal disorders refractory to medical therapy (with video). Gastrointest Endosc 2015;81:1170-1177.

17. Shiwaku H, Inoue H, Beppu R, et al. Successful treatment of diffuse esophageal spasm by peroral endoscopic myotomy. Gastrointest Endosc 2013;77:149-150.

18. Ko WJ, Lee BM, Park WY, et al. Jackhammer esophagus treated by a peroral endoscopic myotomy. Korean J Gastroenterol 2014;64:370-374.

19. Stavropoulos SN, Modayil RJ, Friedel D, Savides T. The international per oral endoscopic myotomy survey (IPOEMS): a snapshot of the global POEM experience. Surg Endosc 2013;27:3322-3338.

20. Ling TS, Guo HM, Yang T, Peng CY, Zou XP, Shi RH. Effectiveness of peroral endoscopic myotomy in the treatment of achalasia: a pilot trial in Chinese Han population with a minimum of one-year follow-up. J Dig Dis 2014;15:352-358.

21. Wang J, Tan N, Xiao Y, et al. Safety and efficacy of the modified peroral endoscopic myotomy with shorter myotomy for achalasia patients: a prospective study. Dis Esophagus 2015;28:720-727. 
22. Liu XJ, Tan YY, Yang RQ, et al. The outcomes and quality of life of patients with achalasia after peroral endoscopic myotomy in the short-term. Ann Thorac Cardiovasc Surg 2015;21:507-512.

23. Ramchandani M, Nageshwar Reddy D, Darisetty S, et al. Peroral endoscopic myotomy for achalasia cardia: treatment analysis and follow up of over 200 consecutive patients at a single center. Dig Endosc 2016;28:19-26.

24. Costamagna G, Marchese M, Familiari P, Tringali A, Inoue H, Perri V. Peroral endoscopic myotomy (POEM) for oesophageal achalasia: preliminary results in humans. Dig Liver Dis 2012;44:827-832.

25. Inoue $\mathrm{H}$, Sato $\mathrm{H}$, Ikeda $\mathrm{H}$, et al. Per-oral endoscopic myotomy: a series of 500 patients. J Am Coll Surg 2015;221:256-264.

26. Shiwaku $\mathrm{H}$, Inoue $\mathrm{H}$, Yamashita $\mathrm{K}$, et al. Peroral endoscopic myotomy for esophageal achalasia: outcomes of the first over 100 patients with shortterm follow-up. Surg Endosc 2016;30:4817-4826.

27. Lee BH, Shim KY, Hong SJ, et al. Peroral endoscopic myotomy for treatment of achalasia: initial results of a Korean study. Clin Endosc 2013;46:161-167.

28. Teitelbaum EN, Soper NJ, Santos BF, et al. Symptomatic and physiologic outcomes one year after peroral esophageal myotomy (POEM) for treatment of achalasia. Surg Endosc 2014;28:3359-3365.

29. Sharata AM, Dunst CM, Pescarus R, et al. Peroral endoscopic myotomy (POEM) for esophageal primary motility disorders: analysis of 100 consecutive patients. J Gastrointest Surg 2015;19:161-170; discussion 170

30. Khashab MA, El Zein M, Kumbhari V, et al. Comprehensive analysis of efficacy and safety of peroral endoscopic myotomy performed by a gastroenterologist in the endoscopy unit: a single-center experience. Gastrointest Endosc 2016;83:117-125.

31. Talukdar R, Inoue H, Nageshwar Reddy D. Efficacy of peroral endoscopic myotomy (POEM) in the treatment of achalasia: a systematic review and meta-analysis. Surg Endosc 2015;29:3030-3046.

32. Barbieri LA, Hassan C, Rosati R, Romario UF, Correale L, Repici A. Systematic review and meta-analysis: efficacy and safety of POEM for achalasia. United European Gastroenterol J 2015;3:325-334.

33. Patel K, Abbassi-Ghadi N, Markar S, Kumar S, Jethwa P, Zaninotto G. Peroral endoscopic myotomy for the treatment of esophageal achalasia: systematic review and pooled analysis. Dis Esophagus 2016;29:807-819.

34. Akintoye E, Kumar N, Obaitan I, Alayo QA, Thompson CC. Peroral endoscopic myotomy: a meta-analysis. Endoscopy 2016;48:1059-1068.

35. Ujiki MB, Yetasook AK, Zapf M, Linn JG, Carbray JM, Denham W. Peroral endoscopic myotomy: a short-term comparison with the standard laparoscopic approach. Surgery 2013;154:893-897; discussion 897-900.

36. Teitelbaum EN, Rajeswaran S, Zhang R, et al. Peroral esophageal myotomy (POEM) and laparoscopic Heller myotomy produce a similar shortterm anatomic and functional effect. Surgery 2013;154:885-891; discussion 891-892.

37. Kumagai K, Tsai JA, Thorell A, Lundell L, Håkanson B. Per-oral endoscopic myotomy for achalasia. Are results comparable to laparoscopic Heller myotomy? Scand J Gastroenterol 2015;50:505-512.

38. Ngamruengphong $\mathrm{S}$, Inoue $\mathrm{H}$, Chiu $\mathrm{PW}$, et al. Long-term outcomes of per-oral endoscopic myotomy in patients with achalasia with a minimum follow-up of 2 years: an international multicenter study. Gastrointest Endosc 2017;85:927-933.e2.

39. Kim WH, Cho JY, Ko WJ, et al. Comparison of the outcomes of peroral endoscopic myotomy for achalasia according to manometric subtype. Gut Liver 2017;11:642-647.

40. Khan MA, Kumbhari V, Ngamruengphong S, et al. Is POEM the answer for management of spastic esophageal disorders? A systematic review and meta-analysis. Dig Dis Sci 2017;62:35-44.

41. Minami H, Inoue H, Haji A, et al. Per-oral endoscopic myotomy: emerging indications and evolving techniques. Dig Endosc 2015;27:175-181.

42. Li H, Linghu E, Wang X. Fibrin sealant for closure of mucosal penetration at the cardia during peroral endoscopic myotomy (POEM). Endoscopy 2012;44 Suppl 2 UCTN:E215-E216.

43. Kurian AA, Bhayani NH, Reavis K, Dunst C, Swanström L. Endoscopic suture repair of full-thickness esophagotomy during per-oral esophageal myotomy for achalasia. Surg Endosc 2013;27:3910.

44. Modayil R, Friedel D, Stavropoulos SN. Endoscopic suture repair of a large mucosal perforation during peroral endoscopic myotomy for treatment of achalasia. Gastrointest Endosc 2014;80:1169-1170.

45. Bechara R, Onimaru M, Ikeda H, Inoue H. Per-oral endoscopic myotomy, 1000 cases later: pearls, pitfalls, and practical considerations. Gastrointest Endosc 2016;84:330-338.

46. Minami H, Isomoto H, Yamaguchi N, et al. Peroral endoscopic myotomy for esophageal achalasia: clinical impact of 28 cases. Dig Endosc 2014;26:43-51.

47. von Renteln D, Fuchs KH, Fockens P, et al. Peroral endoscopic myotomy for the treatment of achalasia: an international prospective multicenter study. Gastroenterology 2013;145:309-311.e3.

48. Eleftheriadis N, Inoue H, Ikeda H, Onimaru M, Maselli R, Santi G. Submucosal tunnel endoscopy: peroral endoscopic myotomy and peroral endoscopic tumor resection. World J Gastrointest Endosc 2016;8:86-103.

49. Li QL, Zhou PH. Perspective on peroral endoscopic myotomy for achalasia: Zhongshan experience. Gut Liver 2015;9:152-158.

50. Onimaru M, Inoue H, Ikeda $\mathrm{H}$, et al. Greater curvature myotomy is a safe and effective modified technique in per-oral endoscopic myotomy (with videos). Gastrointest Endosc 2015;81:1370-1377.

51. Onimaru M, Inoue H, Ikeda H, et al. Peroral endoscopic myotomy is a viable option for failed surgical esophagocardiomyotomy instead of redo surgical Heller myotomy: a single center prospective study. J Am Coll Surg 2013;217:598-605.

52. Eleftheriadis N, Protopapas A, Katsogridakis J, Hatzitolios AI. Successful peroral endoscopic myotomy for radical treatment of sigmoid-type esophageal achalasia by Greek gastroenterologists. Ann Gastroenterol 2014;27:430-431.

53. Li QL, Chen WF, Zhou PH, et al. Peroral endoscopic myotomy for the treatment of achalasia: a clinical comparative study of endoscopic full-thickness and circular muscle myotomy. J Am Coll Surg 2013;217:442-451.

54. Li C, Gong A, Zhang J, et al. Clinical outcomes and safety of partial full-thickness myotomy versus circular muscle myotomy in peroral endoscopic myotomy for achalasia patients. Gastroenterol Res Pract 2017;2017:2676513.

55. Wang XH, Tan YY, Zhu HY, Li CJ, Liu DL. Full-thickness myotomy is associated with higher rate of postoperative gastroesophageal reflux disease. World J Gastroenterol 2016;22:9419-9426.

56. Inoue H, Ikeda H, Hosoya T, et al. Submucosal endoscopic tumor resection for subepithelial tumors in the esophagus and cardia. Endoscopy 2012;44:225-230.

57. Xu MD, Cai MY, Zhou PH, et al. Submucosal tunneling endoscopic resection: a new technique for treating upper GI submucosal tumors originating from the muscularis propria layer (with videos). Gastrointest Endosc 2012;75:195-199.

58. Wang XY, Xu MD, Yao LQ, et al. Submucosal tunneling endoscopic resection for submucosal tumors of the esophagogastric junction originating from the muscularis propria layer: a feasibility study (with videos). Surg Endosc 2014;28:1971-1977.

59. Ye LP, Zhang Y, Mao XL, Zhu LH, Zhou X, Chen JY. Submucosal tunneling endoscopic resection for small upper gastrointestinal subepithelial tumors originating from the muscularis propria layer. Surg Endosc 2014;28:524-530.

60. Khashab MA, Stein E, Clarke JO, et al. Gastric peroral endoscopic myotomy for refractory gastroparesis: first human endoscopic pyloromyotomy (with video). Gastrointest Endosc 2013;78:764-768.

61. Shlomovitz E, Pescarus R, Cassera MA, et al. Early human experience with per-oral endoscopic pyloromyotomy (POP). Surg Endosc 2015;29:543-551.

62. Chaves DM, de Moura EG, Mestieri LH, Artifon EL, Sakai P. Endoscopic pyloromyotomy via a gastric submucosal tunnel dissection for the treatment of gastroparesis after surgical vagal lesion. Gastrointest Endosc 2014;80:164.

63. Jung Y, Lee J, Gromski MA, et al. Assessment of the length of myotomy in peroral endoscopic pyloromyotomy (G-POEM) using a submucosal tunnel technique (video). Surg Endosc 2015;29:2377-2384. 